\title{
Experimental Study on Grinding Force of Zirconia Ceramics in Dry/Wet Grinding Environment
}

\author{
Zhang Junping ${ }^{1}$,Wang Weidong ${ }^{2}$, Li Songhua ${ }^{2},{\text { Han } \mathrm{TaO}^{2}}^{2}$ \\ 'Shanghai Vocational College of Science \& Technology,201800,Shanghai,China; \\ ${ }^{2}$ School of Mechanical Engineering, Shenyang Jianzhu University, 110168,Shenyang,China;
}

\begin{abstract}
The impacts of different linear speed of grinding wheel, grinding depth and workpiece feed speed with or without grinding fluid on grinding force were studied by plane grinding machining of zirconia ceramics. The impacts of different machining environment and grinding parameter on normal and tangential grinding forceswere studied by testing the grinding force during grinding with a force measuring device. The studies showed that the normal and tangential grinding forces decrease with the increase of the linear speed of grinding wheel and increase with the improvement of grinding depth and workpiece feed speed. The grinding depth has the greatest impacts on the normal and tangential grinding forces in dry grinding environment; while in wet grinding environment, the grinding depth exerts the greatest impacts on the normal grinding force and the linear speed of grinding wheel imposes the greatest impacts on the tangential grinding force. In addition, it was found that the normal grinding force in dry grinding is minor than that in wet grinding, that the tangential grinding force in dry grinding is greater than that in wet grinding, and that the grinding force ratio in dry grinding is lower than that in wet grinding.
\end{abstract}

\section{Introduction}

With the development of the times, high-end manufacturing equipment has gradually become the focus of development; and engineering ceramics have been widely applied to the basic components of high-end machine tools by virtue of its excellent performance. Such ceramic materials have such advantages as high hardness, wear resistance, oxidation resistance, corrosion resistance and high temperature resistance [1]. Such materials have broad application prospect in aerospace, national defense and military, industrial and chemical equipment and other fields.

Since engineering ceramics have high hardness and great brittleness, the processing and production of engineering ceramics is a worldwide problem. In practical production, grinding is generally applied to the processing of engineering ceramics [2]. In the process of grinding, the grinding force is a key parameter. The magnitude of grinding force may affect the integrity of the workpiece surface during processing. Therefore, it is very necessary to study the grinding force [3]. For this purpose, this paper focused on the study of the impacts of different grinding parameters on the normal and tangential grinding forces in dry/wet grinding of zirconia ceramics. The factors influencing the normal and tangential grinding forces of zirconia ceramics were studied through a large number of experiments. Besides, this paper tried to find efficient grinding methods suitable for zirconia ceramics.

\section{Experimental Conditions}

Experiments were carried out on the precision forming grinder. The test piece was $20 * 20 * 10 \mathrm{~mm}$ workblanks of zirconia ceramics. The tool was a resin bond diamond grinding wheel with a particle size of D91. Kistler9257B plane force measuring device was used for real-time detection of the grinding force.

\section{EXPERIMENT ON IMPACTS OF GRINDING PARAMETERS ON GRINDING FORCE}

The grinding force is composed of the deformation force of smear metal and the mutual friction on its surface. Since zirconia ceramic materials are hard and brittle, it is difficult to cut over abrasive particles during grinding. Such materials are removed mostly in a brittle manner and rarely in a plastic manner. Therefore, when analyzing the grinding of zirconia ceramics, the grinding force mainly is friction [4].

L9 $\left(3^{3}\right)$ orthogonal experiment was adopted. The scheme and results of the orthogonal experiment are as shown in Table 1. In order to improve the accuracy of experimental data, repeated experiments were carried out for each group of experiments. The experimental data with large deviation were removed; and the averages of the remaining data were regarded as experimental results. 
Table 1 Scheme and Results of Orthogonal Experiment

\begin{tabular}{|c|c|c|c|c|c|c|c|}
\hline $\begin{array}{l}\text { Number of } \\
\text { experiment }\end{array}$ & $\begin{array}{c}\text { Linear speed } \\
\text { of grinding } \\
\text { wheel } /[\mathrm{m} / \mathrm{s}]\end{array}$ & $\begin{array}{c}\text { Grinding } \\
\text { depth/[mm] }\end{array}$ & $\begin{array}{l}\text { Workpiece } \\
\text { feed speed } \\
/[\mathrm{mm} / \mathrm{min}]\end{array}$ & $\begin{array}{l}\text { Normal } \\
\text { grinding } \\
\text { force in } \\
\text { wet } \\
\text { grindin- } \\
\mathrm{g} /[\mathrm{N}]\end{array}$ & $\begin{array}{l}\text { Tangenti- } \\
\text { al grinding } \\
\text { force in } \\
\text { wet } \\
\text { grinding/[ } \\
\mathrm{N}]\end{array}$ & $\begin{array}{l}\text { Norm- } \\
\text { al } \\
\text { grindi- } \\
\text { ng } \\
\text { force in } \\
\text { dry } \\
\text { grind- } \\
\text { ing/[N] }\end{array}$ & $\begin{array}{l}\text { Tangen- } \\
\text { tial } \\
\text { grinding } \\
\text { force in } \\
\text { dry } \\
\text { grinding/[ } \\
\quad \mathrm{N}]\end{array}$ \\
\hline 1 & 30 & 0.005 & 1000 & 251 & 31 & 96 & 35 \\
\hline 2 & 30 & 0.010 & 3000 & 448 & 34 & 245 & 70 \\
\hline 3 & 30 & 0.015 & 5000 & 653 & 58 & 383 & 85 \\
\hline 4 & 40 & 0.005 & 3000 & 320 & 30 & 145 & 32 \\
\hline 5 & 40 & 0.010 & 5000 & 452 & 33 & 295 & 60 \\
\hline 6 & 40 & 0.015 & 1000 & 459 & 36 & 200 & 40 \\
\hline 7 & 50 & 0.005 & 5000 & 201 & 20 & 160 & 29 \\
\hline 8 & 50 & 0.010 & 1000 & 352 & 23 & 135 & 30 \\
\hline 9 & 50 & 0.015 & 3000 & 495 & 31 & 260 & 65 \\
\hline
\end{tabular}

The response tables for the normal and tangential grinding forces in dry/wet grinding should be established normal and tangential grinding forces. The response tables for the normal and tangential grinding forces in to accurately judge the impacts of grinding parameters on dry/wet grinding are as shown in Tables 2 and 3 .

Table 2 Response Table for Fn and Ft in Dry Grinding

\begin{tabular}{ccccccc}
\hline Level & $\begin{array}{c}\text { Linear speed of grinding wheel } \\
{[\mathrm{m} / \mathrm{s}]}\end{array}$ & \multicolumn{2}{c}{$\begin{array}{c}\text { Grinding depth } \\
{[\mathrm{mm}]}\end{array}$} & \multicolumn{2}{c}{$\begin{array}{c}\text { Workpiece feed speed } \\
{[\mathrm{mm} / \mathrm{min}]}\end{array}$} \\
\hline Grinding force & Fn & Ft & Fn & Ft & Fn & Ft \\
\hline 1 & 241 & 63 & 134 & 32 & 143 & 35 \\
2 & 213 & 44 & 225 & 53 & 216 & 56 \\
3 & 185 & 41 & 281 & 63 & 279 & 58 \\
Range & 56 & 22 & 147 & 31 & 136 & 23 \\
\hline
\end{tabular}

Table 3 Response Table for Fn and Ft in Wet Grinding

\begin{tabular}{ccccccc}
\hline Level & $\begin{array}{c}\text { Linear speed of grinding wheel } \\
{[\mathrm{m} / \mathrm{s}]}\end{array}$ & \multicolumn{2}{c}{$\begin{array}{c}\text { Grinding depth } \\
{[\mathrm{mm}]}\end{array}$} & \multicolumn{2}{c}{$\begin{array}{c}\text { Workpiece feed speed } \\
{[\mathrm{mm} / \mathrm{min}]}\end{array}$} \\
\hline Grinding force & Fn & Ft & Fn & Ft & Fn & Ft \\
\hline 1 & 450 & 41 & 257 & 27 & 354 & 30 \\
2 & 410 & 29 & 417 & 30 & 421 & 32 \\
3 & 349 & 25 & 535 & 41 & 435 & 37 \\
Range & 101 & 16 & 278 & 14 & 81 & 7 \\
\hline
\end{tabular}

In wet grinding environment, grinding depth has the greatest impacts on the normal grinding force, while the linear speed of grinding wheel exerts the greatest impacts on the tangential grinding force. If the range of grinding depth, the linear speed of grinding wheel and workpiece feed speed decreases in order, the impacts on the normal grinding force are gradually weakened; if the range of the linear speed of grinding wheel, grinding depth and

\section{Analysis of Experimental Results}

workpiece feed speed decreases in turn, the impacts on the tangential grinding force are gradually weakened.

In dry grinding environment, grinding depth imposes the greatest impacts on the tangential and normal grinding force. If the range of grinding depth, workpiece feed speed and the linear speed of grinding wheel decreases in order, the impacts on tangential and normal grinding force are gradually weakened.

\subsection{Impacts of linear speed of grinding wheel on grinding force}

It can be seen from Fig. 1 that in both wet and dry grinding environment, the tangential and normal grinding 
force in grinding zirconia ceramics decreases with the improvement of the linear speed of grinding wheel. In order the study this case, the theory of the maximum thickness of undeformed smear metal in grinding dmax was introduced [5]. It may be formulated as follows:

$$
\mathrm{d}_{\max }=\{3 / \operatorname{ctana}\}^{1 / 2}\left\{v_{\mathrm{w}} / v_{\mathrm{s}}\right\}^{1 / 2}\left\{\mathrm{a}_{\mathrm{\rho}} / \mathrm{d}_{\mathrm{s}}\right\}^{1 / 4}
$$

Where: $c$ is the number of effective grains on the grinding contact area; a is the half-angle of the cross section of undeformed smear metal; a $\rho$ is the grinding depth; and ds is the diameter of the grinding wheel [6]. The grinding force of single grain increases with the increase of the maximum undeformed cutting thicknessdmax. It can be seen from Formula (1) that if the linear speed of grinding wheel increases and other parameters remain the same, the value of dmax will decrease; the grinding force decreases with the increase of the linear speed of grinding wheel for the variation trend of the maximum undeformed cutting thickness is the same as that of grinding force; when the linear speed of grinding wheel increases to a certain extent, with the further increase of the linear speed of grinding wheel, the variation of maximum undeformed cutting thickness is no longer obvious, thus the grinding force diagrams show a slow downward trend. In dry grinding, with the rise of the temperature on workpiece surface, the removal method in grinding gradually shifts from brittle removal to plastic removal to increase the tangential grinding force. Therefore, the tangential grinding force in dry grinding is greater than that in wet grinding. Consequently, relative greater linear speed of grinding wheel may be used in grinding process, which can not only reduce the grinding force and improve the surface quality, but also improve the removal rate of materials.

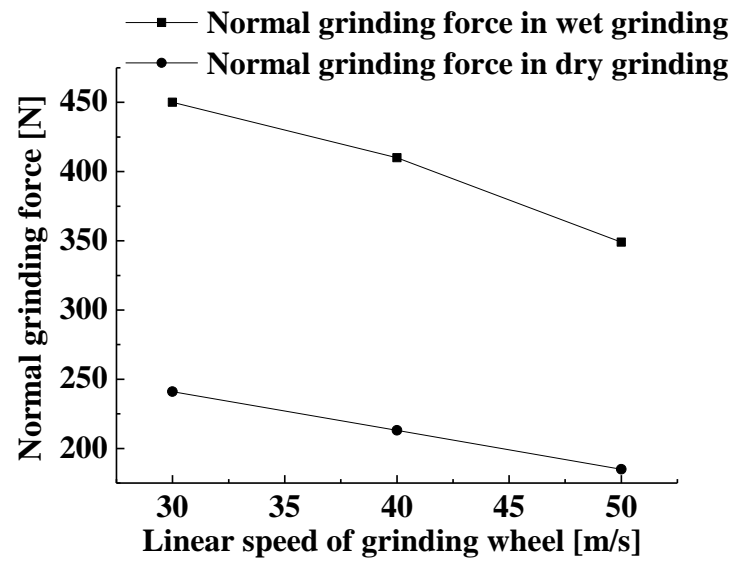

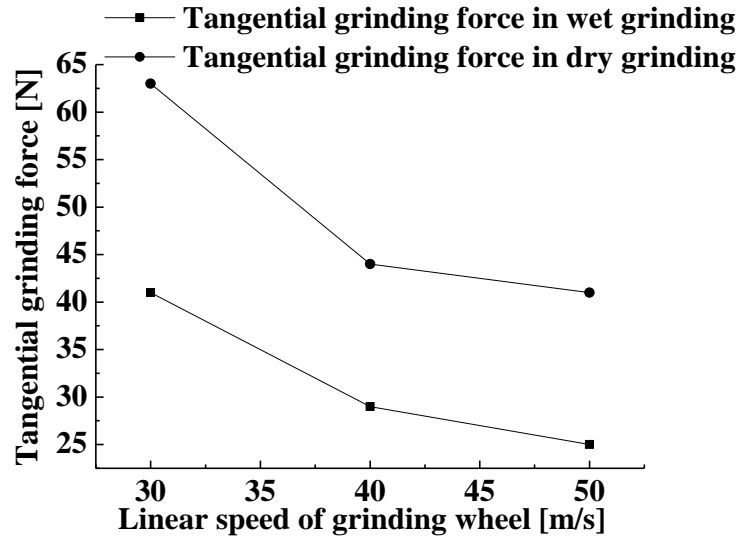

Fig. 1 Impacts of Linear Speed of Grinding Wheel on Normal and Tangential Grinding Forces

\subsection{Impacts of grinding depth on grinding force}

In both wet and dry grinding environment, with the gradual increase of grinding depth, the normal and tangential grinding forces in grinding zirconia ceramics gradually increase as shown in Fig. 2. When the grinding depth increases, the normal and tangential grinding forces also increase; and the grinding depth has greater impacts on the normal grinding force. This is because when the grinding depth is smaller, the ceramic materials are removed by the slight plastic deformation, thus the grinding force is relatively small. The removal mechanism of zirconia materials in grinding changes with the gradual increase of grinding depth. It can be seen from experimental study that if the grinding depth gradually increases and exceeds a certain critical value, the material removal method in grinding zirconia ceramics gradually shifts from plastic deformation to brittle shedding. This may impose certain impacts on the normal grinding force. The increase of the normal grinding force is because with the gradual increase of grinding depth, the number of effective grains involved in grinding and the contract area between grains and workpiece surface increase accordingly. In dry grinding environment, with the gradual increase of grinding depth and due to the absence of cooling liquid, the grinding temperature rises sharply, which will cause phase change on zirconia surface in grinding process. In such case, the removal method will be gradually converted from brittle removal to brittle-plastic removal, which increases the tangential grinding force. Therefore, the tangential grinding force in dry grinding is greater than that in wet grinding. In order to improve the surface quality of grinding ceramic materials, small grinding depth should be selected. It would be best if the grinding depth is below the critical grinding depth, thus zirconia ceramics can be removed through ideal plastic deformation [7]. 

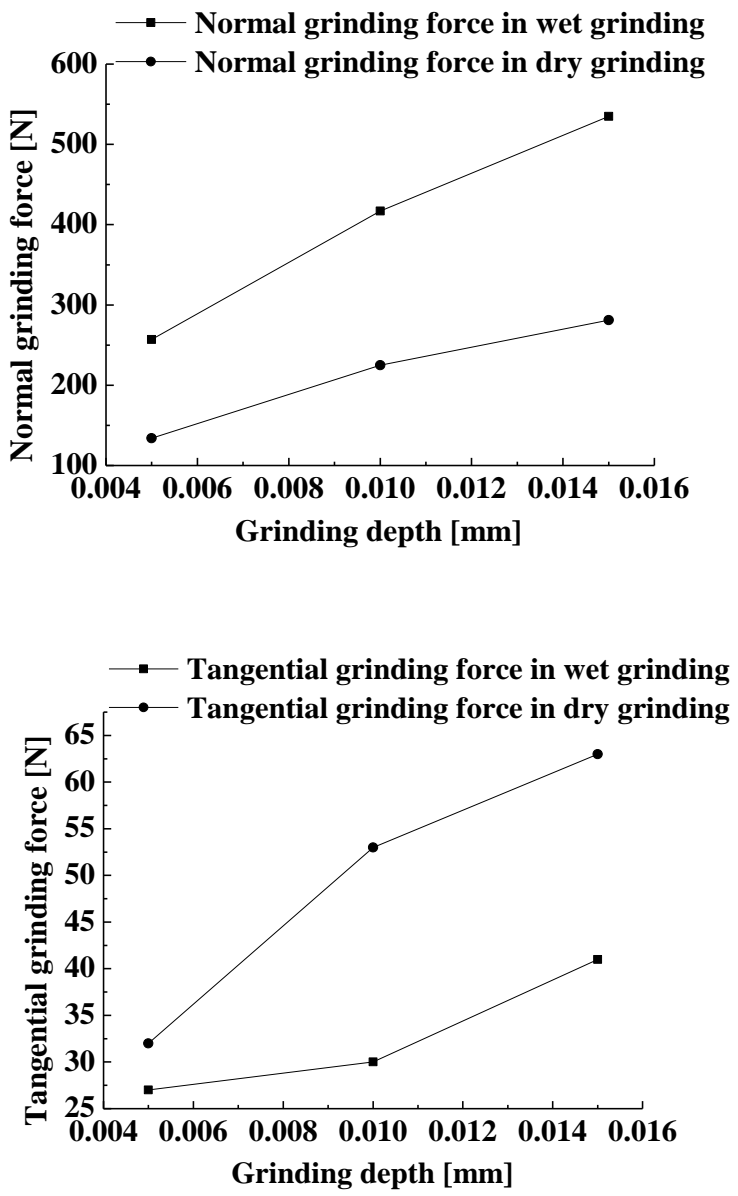

Fig. 2 Impacts of Grinding Depth on Normal and Tangential Grinding Forces

\subsection{Impacts of workpiece feed speed on grinding force}

In wet and dry grinding environment, the tangential and normal grinding forces in grinding zirconia ceramics increase with the increase of workpiece feed speed as shown in Fig. 3. The normal grinding force in wet grinding of zirconia ceramics is greater than that in dry grinding, but the tangential grinding force in dry grinding of zirconia ceramics is greater than that in wet grinding. This is because when the workpiece feed speed is low and with slow temperature rise, zirconia ceramics are mainly removed by plastic removal. The tangential and normal grinding forces increase with the improvement of workpiece feed speed; and the change is obvious. In dry grinding, with the improvement of workpiece feed speed, the grinding temperature also rises, making the removal method for zirconia ceramics workpieces gradually shift from brittle removal to plastic removal. In this way, the tangential grinding force in dry grinding is greater than that in wet grinding.
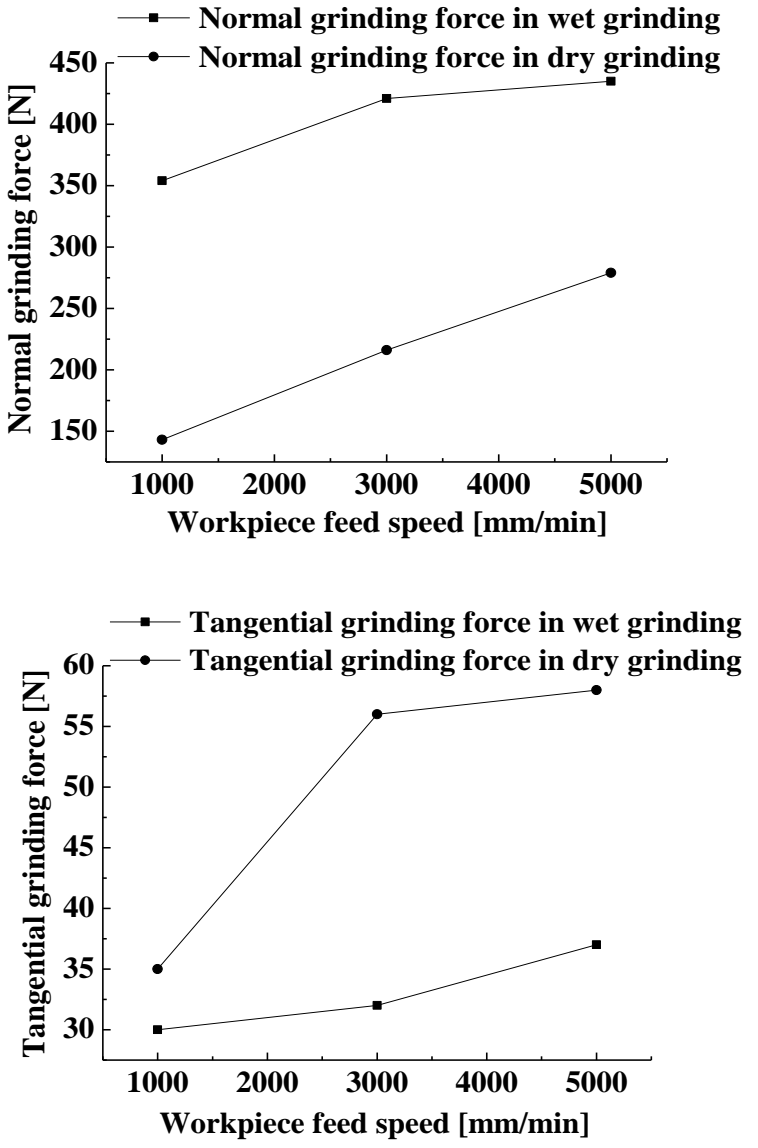

Fig. 3 Impacts of Workpiece Feed Speed on Normal and Tangential Grinding Forces

\subsection{Impacts of dry/wet grinding environment on grinding force ratio}

The grinding force ratio can reflect the wear of the grinding wheel and the difficulty level during the grinding. The grinding ratio is defined as the ratio of the normal grinding force $\mathrm{Fn}$ to the tangential grinding force Ft. The grinding force ratio in dry/wet grinding environment can be calculated by the data in Table 1 . As shown in Fig. 4, it can be clearly found that when grinding zirconia ceramics, the grinding force ratio in wet grinding is greater than that in dry grinding. It can be concluded from the correlation between the grinding force ratio and the difficulty level in grinding the material that the grinding effects without grinding fluid in grinding of zirconia ceramics are better that those with grinding fluid. According the analysis above, a lot of heat will be generated in the grinding process due to the continuous friction and cutting between the grinding wheel and ceramic surface. If there is no cooling liquid, the surface of zirconia ceramics will be softened, thus the removal method for such material will change from brittle removal to plastic removal. In such case, the machinability of zirconia ceramics is improved. 


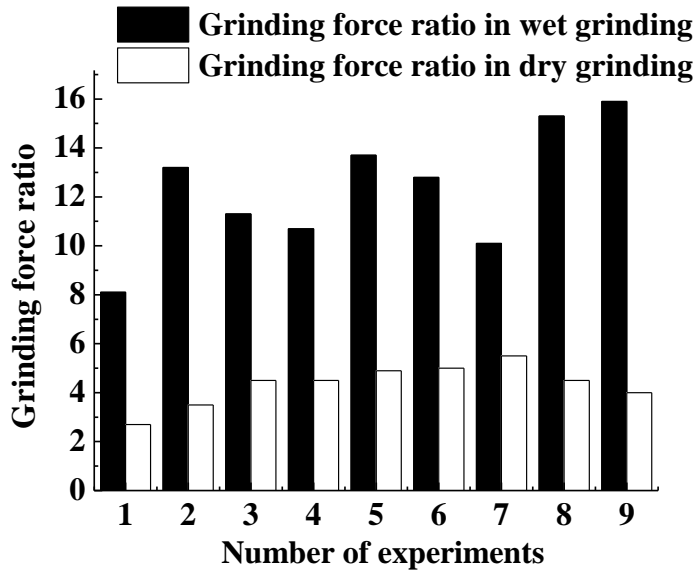

Fig. 4 Comparison of Grinding Force Ratio in Dry/Wet Grinding Environment

\section{Conclusions}

When grinding zirconia ceramics, the normal and tangential grinding forces are negatively correlated to the linear speed of the grinding wheel and positively correlated to the workpiece feed speed.In wet grinding, the impacts of the grinding depth, the linear speed of the grinding wheel and the workpiece feed speed on the normal grinding force gradually weakens; and the impacts of the linear speed of the grinding wheel, the grinding depth and the workpiece feed speed on the tangential grinding force gradually weakens. In dry grinding, the major and minor order of the impacts of various process parameters on the tangential and normal grinding forces is the grinding depth, the workpiece feed speed and the linear speed of the grinding wheel.The tangential grinding force in dry grinding is greater than that in wet grinding, while the normal grinding force in dry grinding is minor than that in wet grinding. Dry grinding is easier for grinding zirconia ceramics than wet grinding.

\section{References}

1. YUAN Jiulong, Zhang feihu, Development Research of Science and Technologies in Ultraprecision Machining Field, J. Journal Of Mechanical Engineering, 46 (2010) 161-176.

2. Hou Yonggai, Tian Jiugen, The Current Research Status of Zirconia Ceramics Grinding, J. China Ceramic, 50 (2014) 6-9.

3. Bahman Azarhoushang, Amir Daneshi, Dal Ho Lee, Evaluation of thermal damages and residual stresses in dry grinding by structured wheels, J. Journal of Cleaner Production, 11 (2016).

4. Zhang Ningju, Zhao Meilin, The Optimization Of Grinding Dosage On Grinding Hardening, J. Journal of Mechanical Strength, 38 (2016) 526-530.

5. WANG Yu, WU Yuhou, Experimental Studdy on Inner Grinding Force of Zirconia Ceramic Bearing Rings, J. Machinery Design \& Manufacture, 9 (2015) 159-165.

6. WU Yuhou,WANG Kai. Experimental Study on Grinding Force of HIPSN Engineering Ceramics by Internal Grinding, J. Journal of Shenyang Jianzhu University, Natural Science, 5 (2008) 863-867.

7. Wu Shuan, Zhu Xijing, Modelling Analysis on Ductile Removal of Hardbrittle Material by Single Grain, J. Surface Technology, 45 (2016) 219-223. 